\title{
Eye Care Seeking Behavior on Prevention of Blindness among Elderly in Urban Area of Magway Township, Myanmar
}

\author{
Kyaw Ko Ko ${ }^{{ }^{*}}$, Sutham Nanthamonkolchai ${ }^{2}$, Chokchai Munsawaengsub ${ }^{3}$ \\ ${ }^{1}$ Deputy Project Manager, Handicap International Myanmar, Yangon, Myanmar \\ ${ }^{2}$ Faculty of Public Health, Mahidol University, Bangkok, Thailand \\ ${ }^{3}$ Faculty of Public Health, Mahidol University, Bangkok, Thailand
}

\begin{abstract}
Received: 30 November, 2017; Accepted: 17 December, 2017; Published: 03 January, 2018
*Corresponding author: Kyaw Ko Ko, Deputy Project Manager, Handicap International Myanmar, Yangon, Myanmar, Tel.: +959974731464; E-mail: kyawkopp@gmail.com
\end{abstract}

\begin{abstract}
This cross-sectional study was intended to identify the eye care seeking behavior among the elderly in urban area of Magway Township, Myanmar. This study used stratified random sampling method. The population consisted of 196 elderly from 4 areas in Magway Township who were interviewed through the use of a structured questionnaire during the period from 1 April to 30 April 2015. Chi-square and Fisher-exact test analysis were carried out to determine the association between the independent variables and eye care seeking behavior. The result revealed that current rate of seeking eye care was $87.4 \%$ among elderly who had eye problems within last one year (87 out of 196) in this area. Refractive error was the leading eye problems (17.3\%), followed by cataract $(13.8 \%)$, by eye trauma $(7.1 \%)$, glaucoma $(5.6 \%)$, red eye $(2.6 \%)$, eye irritation (1\%) and night blindness, retinal degeneration and corneal ulcer are $0.5 \%$ respectively. This study indicates that empowerment and strengthening of health care personnel, implementation of primary eye care training for community health volunteers, enhancing eye health education program at each level including primary care unit level and updating knowledge and skills of health staff on primary eye care by providing refresher training program.
\end{abstract}

Keywords: Eye Care Seeking Behavior; Prevention of Blindness; Elderly, Myanmar;

\section{Introduction}

Older persons' numbers are increasing rapidly in the whole world. The older population of the more developed regions tripled between 1950 and 2013, from 94 million to 287 million, and it will increase further in coming decades, reaching 417 million in 2050 [1]. The proportion of elderly population (over 60 years) in Myanmar in 2014 was 8.8 percent in the same year and according to UN projections, by 2030 it will increase to $15 \%$ of the population, and by 2050 older people will consist of a quarter of Myanmar's total population. Shortly after 2035, persons aged 60 and older will be more than children under age 15 [2]. In Myanmar, increasing age plays as a major risk factor for blindness, visual impairment, cataract, glaucoma and trachoma [3]. Approximately one person in three has some form of vision- reducing eye disease by the age of 65 [4]. Diabetic retinopathy may be observed in the elderly at the time of diagnosis or during the first few years of diabetes [4].

Approximately, 285 million of people are visually impaired in the whole world: 39 million are blind and 246 have poor vision [5]. So, communities also suffer from the financial effects of blindness [6]. Major five leading causes of blindness in the world are cataract, glaucoma, trachoma, onchoceriasis and vitamin A deficiency [7]. Blindness has been described to be the results of suffering from different main eye diseases, which is directly, associated with poor eye care seeking behavior and utilization of eye care services [6].

In Myanmar, there are Yangon Eye Hospital and Mandalay Eye and ENT hospital and two Prevention of Blindness hospitals, i.e. one in Bago Secondary Eye Centre and General Hospital and another in Sagaing Secondary Eye Centre. Apart from this, there are limited service providers in private practice [3]. It is estimated that about 132.6 people per 100,000 population suffer new eye diseases in every year [8]. The prevalence of blindness or loss of eye sight is $4.8 \%$ in 2012. According to the eye study in rural area of Meiktila Myanmar, it should be done to empower blind people and communities [9].

Magway Township situated in the central dry region of Myanmar, near the Ayeyarwaddy River. And, there are also university of medicine, Magway and teaching hospital [10]. Morbidity rate of new eye diseases per 100,000 population is also 51.3. Population over 60 years of age is $5 \%$ of total population in both urban and rural area [2]. According to the data from the eye department of Magway Divisional Hospital in 2013, number of out-patient is 1686 and 839 is in-patient. But, there are no precise data and research to assess the eye care seeking behavior on prevention of blindness in that region. Thus, this is one factor to develop this study in this region.

The elderly care, as one of the target population in Myanmar, was aimed to promote active and healthy aging by the elderly 
health care project of ministry of health since 1992-93. This program is based on comprehensive health care: promotive, preventive, curative and rehabilitative care. In 2013, 161 townships were under the coverage of this program in which the Township and Station Hospitals and Rural Health Centers [8]. Since sufficient studies have not been conducted concerning eye care seeking behavior, especially among elderly, adequate information been hard to access.

Therefore, this study aimed to help in enhancing coverage of primary eye care of blindness and its associated factors among people living in Magway Township. The objective of the study was to identify the eye care seeking behavior on prevention of blindness among elderly in urban area of Magway Township, Magway Division and Myanmar. The result of the study provided for closing the disparity in the eye seeking behavior on this critical area of public health concern.

\section{Materials and Methods}

\section{Study Design and Setting}

This study was a cross-sectional study to access the eye care seeking behavior on prevention of blindness among elderly and its associated factors. The data was collected by face-to-face interview with semi-structured questionnaires.

\section{Sampling method}

Cluster sampling method was used in this study. There were 4022 people over 60 years and 12060 households in the urban area of the township. From the sample size calculation, 195 samples were needed for the study and they were proportionately allocated to each ward according to selected wards population over 60 years.

The first sample house was selected randomly among number 1 and household interval 10 unit of respective ward. After obtaining the first start number, it was checked from the household list obtained from authorities. The following sample houses were selected from that household list according to household interval.

Only one selected subject was asked in one household according to selection criteria. If selected sample was missing, the interviewer visited to that house second times and if still not available, choose the household head if he/she was not selected one or if he/she was selected one, the one next to the household head from register's household list was chosen.

\section{Study Tools}

Questionnaires were developed in consistent with operational definitions of variables. Some questions were modified based on questionnaires of previous studies. They were developed after consultation with advisors and experts for its contents, explanation and appropriate wording.

Pre-test of questionnaires was done on 30 respondents who had similar general characteristics as the study population. The purpose for doing pre-test was to find out the problems concerning the structure, component, respondents understanding and revised according to need. The reliability of knowledge and attitude were tested by Cronbach's coefficient of Alpha.

\section{Ethical Consideration}

Consent to participate was voluntary for all respondents. The ethical aspects of this study were approved by the Ethical Committee for human research, Faculty of Public Health, Mahidol University with certificate of approval number MUPH 2015-082 and protocol number 63/2558.

\section{Method of data collection and quality}

To achieve the objectives of this study, the data was collected following the household visit by administering interviewer assisted structured questionnaire. Five Local Health Volunteers (LHVs) of Magway Township having graduate education and experience on collecting health information data from the community was selected and trained before going to the community to conduct the interviews. The time taken for each interview was about 20-25 minutes. To administer the interviews effectively and collecting reliable and valid data, cooperation and support from local community leaders, Local organizations, Health personnel, LHVs and other community volunteers was sought.

\section{Results}

The general characteristics of the respondents in this study age, sex, marital status, educational level, occupation, family income and number of household members which were described in Table 1.

According to the level of knowledge, the respondents who had good, fair and poor knowledge were $30.6 \%, 57.7 \%$ and $11.7 \%$ respectively. $67.9 \%$ of the respondents had positive attitude towards eye care seeking behavior and $32.1 \%$ of the respondents had negative attitude. Regarding overall social support, majority (44.4\%) respondents had been getting good social supports followed by fair (38.8\%) and poor (16.8\%). Half (50.5\%) of the respondents felt that they had somehow difficulties to access eye care followed by easy access $(45.4 \%)$ and access with great difficulties (4.1\%).

Of all respondents, 55.6\% respondents said that they had no eye problems within last one year. The elderly who had any eye problems (44.4\%) within last one year, refractive error (17.3\%) was found to be leading eye diseases; however, the proportions of other eye diseases were not high. Cataract was found to be second leading diseases $(13.8 \%)$ followed by eye trauma (7.1\%), glaucoma $(5.6 \%)$, red eye $(2.6 \%)$, eye irritation $(1 \%)$ and night blindness; retinal degeneration and corneal ulcer are $0.5 \%$ respectively. Concerning seeking for eye care who had eye problems within last one years, $87.4 \%$ were found who sought eye care. The results regarding the place for seeking eye care who had eye problems within last one years and had received eye care services ( 76 out of 87 who sought eye care) shows private hospital where eye care services available found to be first place 
Eye Care Seeking Behavior on Prevention of Blindness among Elderly in

Table 1 General characteristics of the respondents $(n=196)$

\begin{tabular}{|c|c|c|}
\hline General Characteristics & Number & Percent \\
\hline \multicolumn{3}{|l|}{ Age (in years) } \\
\hline $60-69$ & 132 & 67.3 \\
\hline $70-79$ & 48 & 24.5 \\
\hline$\geq 80$ & 16 & 8.2 \\
\hline
\end{tabular}

Mean=68.2 $\mathrm{SD}=6.4 \mathrm{Min}=60 \mathrm{Max}=90$

Sex

\begin{tabular}{|l|c|c|}
\hline Male & 87 & 44.4 \\
\hline Female & 109 & 55.6 \\
\hline
\end{tabular}

Marital Status

\begin{tabular}{|l|c|c|}
\hline Single & 22 & 11.2 \\
\hline Married & 127 & 64.8 \\
\hline Widowed & 47 & 24 \\
\hline Education & & \\
\hline Illiterate & 9 & 4.6 \\
\hline Primary School & 77 & 39.3 \\
\hline Secondary School & 34 & 17.3 \\
\hline High School & 45 & 23 \\
\hline Graduated & 31 & 15.8 \\
\hline Occupation & 117 & \\
\hline House works & 4 & 59.8 \\
\hline Farmer & 54 & 27.6 \\
\hline Retired & 8 & 4.1 \\
\hline Labour & 3 & 1.5 \\
\hline Unemployed & & \\
\hline
\end{tabular}

Number of household members

\begin{tabular}{c|c|c|}
\hline $1-3$ & 75 & 38.3 \\
\hline $4-6$ & 100 & 51 \\
$\geq 7$ & 21 & 10.7 \\
\hline
\end{tabular}

Family income (Kyats/ month)

\begin{tabular}{|l|c|c|}
\hline$\leq 50000$ & 82 & 41.9 \\
\hline $50001-100000$ & 72 & 36.7 \\
\hline$>100000$ & 39 & 19.9 \\
\hline Non-response & 3 & 1.5 \\
\hline Mean=97400, SD=104900, Min=20000, Max=1000000 \\
\hline Eye problems on these days \\
\hline Yes & 102 & 52 \\
\hline No & 94 & 48 \\
\hline
\end{tabular}

Types of eyes problems on these days

\begin{tabular}{|l|c|c|}
\hline Cataract & 33 & 16.8 \\
\hline Glaucoma & 16 & 8.2 \\
\hline Injury & 15 & 7.7 \\
\hline Night blindness & 1 & 0.5 \\
\hline Refractive error & 42 & 21.4 \\
\hline Blindness & 1 & 0.5 \\
\hline Others & 3 & 1.5 \\
\hline
\end{tabular}

of receiving eye care for more than half (78.9\%) followed by government hospital (14.5\%), eye screening program (5.3\%) and health center (1.3\%).

Table 2 shows that there was no significant association between level of knowledge and eye care seeking among elderly who had eye problems within last one year. Though no statistical significant association identified ( $\mathrm{p}$ - value $>0.05$ ), but almost all (96.4\%) elderly who had good knowledge level were more likely to seek eye care than those who had knowledge level of still need to be improved (83.1\%).

Table 2: Association between level of knowledge and eye care seeking among elderly $(n=87)$

\begin{tabular}{|c|c|c|c|c|c|c|}
\hline & & \multicolumn{5}{|c|}{ Seeking eye care } \\
\hline \multicolumn{2}{|c|}{ Level of knowledge } & \multirow[b]{2}{*}{ Yes } & & \multirow[b]{2}{*}{ No } & & \multirow[b]{2}{*}{ p-value* } \\
\hline & & & & & & \\
\hline & Total & $\mathbf{N}$ & $\%$ & $\mathbf{N}$ & $\%$ & \\
\hline Good & 28 & 27 & $96.40 \%$ & 1 & $3.60 \%$ & \\
\hline \multirow{2}{*}{$\begin{array}{l}\text { Need to be } \\
\text { improved }\end{array}$} & & & & & & 0.079 \\
\hline & 59 & 49 & $83.10 \%$ & 10 & $16.90 \%$ & \\
\hline
\end{tabular}

*p-value by Chi-square test

Table 3 shows association between level of attitude towards eye problems and eye care seeking among elderly who had eye problems within last one year. Though there was no statistical significant association ( $p$ - value $>0.05$ ), but more than threefourth $(88.9 \%)$ elderly who had positive attitude towards eye problems were more likely to seek eye care services than those who had negative attitude (83.3\%).

Table 3: Association between level of attitude towards eye problems and eye care seeking $(\mathrm{n}=87)$

\begin{tabular}{|l|c|c|c|c|c|c|}
\hline Level of attitude & \multicolumn{5}{l|}{ Seeking eye care } \\
\hline & & \multicolumn{2}{|l|}{ Yes } & \multicolumn{2}{l|}{ No } & p-value* \\
\hline & Total & N & $\%$ & N & $\%$ & \\
\hline & 63 & 56 & $88.90 \%$ & 7 & $11.10 \%$ & \\
\hline Positive ( $290 \%)$ & & & & & & 0.486 \\
\hline Negative <90\%) & 24 & 20 & $83.30 \%$ & 4 & $16.70 \%$ & \\
\hline *p-value by Chi-square test & & & & & \\
\hline
\end{tabular}

Table 4: Association between social support and seeking eye care $(n=87)$

\begin{tabular}{l|l|c|c|l|l|l|}
\hline \multicolumn{5}{|l|}{ Social supports } & \multicolumn{5}{l|}{ Seeking eye care } & p-value* \\
\hline & Total & Nes & $\%$ & N & $\%$ & \\
\hline Good & 27 & 20 & $74.10 \%$ & 7 & $25.90 \%$ & \\
\hline Poor & & & & & $0.031 * *$ & \\
\hline & 60 & 56 & $93.30 \%$ & 4 & $6.70 \%$ & \\
\hline
\end{tabular}


Table 4 shows that there is statistical significant association between social supports and seeking eye care among elderly who had eye problems within last one year ( $p$-value $=0.031)$. More than nine out of ten (93.3\%) elderly who had poor social supports were identified to seek eye care than those (74.1\%) elderly who had good social support.

Table 5 shows that there is no statistically significant association between accessibility on eye care services and seeking eye care. The elderly (93.5\%) who had easy access to eye care services were more likely to seek eye care than those who had difficult access to eye care (80.5\%). Nine out of ten elderly $(90.1 \%)$ who can afford the cost of eye care were identified as seeking eye care whenever those who cannot afford (75\%). $89.5 \%$ of the elderly who can afford the cost of travel were more likely to seek eye care than those who cannot afford (72.7\%).

Table 5: Association between accessibility on eye care services and eye care seeking among elderly $(n=87)$

\begin{tabular}{|c|c|c|c|c|c|c|}
\hline \multirow{2}{*}{$\begin{array}{c}\text { Accessibility on eye care } \\
\text { services }\end{array}$} & \multirow{3}{*}{ Total } & \multicolumn{2}{|c|}{ Seeking eye care } & \multirow[b]{2}{*}{ No } & \multirow{3}{*}{$\%$} & \multirow{3}{*}{ p-value ${ }^{*}$} \\
\hline & & Yes & & & & \\
\hline & & $\mathbf{N}$ & & $\mathbf{N}$ & & \\
\hline
\end{tabular}

Distance of the nearest hospital with ECS

\begin{tabular}{|c|c|c|c|c|c|c|}
\hline$\leq 3$ miles & 81 & 70 & $86.40 \%$ & 11 & $13.60 \%$ & \multirow{2}{*}{0.334} \\
\hline$>3$ miles & 6 & 6 & $100.00 \%$ & 0 & $0.00 \%$ & \\
\hline \multicolumn{7}{|l|}{ Modes of transportation } \\
\hline Public & 28 & 23 & $82.10 \%$ & 5 & $17.90 \%$ & \multirow{2}{*}{0.313} \\
\hline Own & 59 & 53 & $89.80 \%$ & 6 & $10.20 \%$ & \\
\hline \multicolumn{7}{|c|}{ Convenience of transportation } \\
\hline Inconvenient & 5 & 4 & $80.00 \%$ & 1 & $20.00 \%$ & \multirow{2}{*}{0.61} \\
\hline Convenient & 82 & 72 & $87.80 \%$ & 10 & $12.20 \%$ & \\
\hline \multicolumn{7}{|l|}{ Cost of the travel } \\
\hline Unaffordable & 11 & 8 & $72.70 \%$ & 3 & $27.30 \%$ & \multirow{2}{*}{0.118} \\
\hline Affordable & 76 & 68 & $89.50 \%$ & 8 & $10.50 \%$ & \\
\hline Unaffordable & 16 & 12 & $75.00 \%$ & 4 & $25.00 \%$ & \multirow{2}{*}{0.1} \\
\hline Affordable & 71 & 64 & $90.10 \%$ & 7 & $9.90 \%$ & \\
\hline \multicolumn{7}{|c|}{ Time of waiting for receiving eye care } \\
\hline$\leq 2$ hours & 58 & 51 & $87.90 \%$ & 7 & $12.10 \%$ & \multirow{2}{*}{0.82} \\
\hline$>2$ hours & 29 & 25 & $86.20 \%$ & 4 & $13.80 \%$ & \\
\hline \multicolumn{7}{|c|}{ Access to eye care services } \\
\hline Difficult & 41 & 33 & $80.50 \%$ & 8 & $19.50 \%$ & \multirow{2}{*}{0.069} \\
\hline Easy & 46 & 43 & $93.50 \%$ & 3 & $6.50 \%$ & \\
\hline
\end{tabular}

Factors associated with eye care seeking behavior were identified by chi-square test and fisher-exact test for association between eye care seeking behavior and other independent variables which were shown by table 6 .

\section{Discussion}

As the principal researcher was fully involved with all steps of research along with data collection though having communication problems because some respondents were too old, it has been found that most of the elderly have not perceived that they have any eye diseases though the burden of eye diseases (on the basic of investigator's and interviewer's observation). In this study, it was obvious that the elder group was less likely to seek eye care because they thought that it has not affected their daily life and they are too old to go to eye care services.

Education of the respondents plays an important role in seeking eye care. Concerning the level of education in this study, the respondents who were literate were seeking eye care than those who were not literate. Concerning about the family income of the respondents, there was no significant association between family income and seeking eye care. It may be because the respondents in this area were getting eye care services from 
Eye Care Seeking Behavior on Prevention of Blindness among Elderly in Urban Area of Magway Township, Myanmar

Table 6: Associated factors for first place of receiving eye care services among elderly

\begin{tabular}{|c|c|c|c|c|c|c|}
\hline \multicolumn{2}{|l|}{ Associated factors } & \multicolumn{2}{|c|}{ Eye care from government } & \multicolumn{2}{|c|}{ Eye care from private } & \multirow[t]{2}{*}{ p-value } \\
\hline & Total & $\mathbf{N}$ & $\%$ & $\mathbf{N}$ & $\%$ & \\
\hline \multicolumn{7}{|l|}{ Household member } \\
\hline$\leq 4$ & 46 & 14 & $30.40 \%$ & 32 & $69.60 \%$ & $0.013^{*}$ \\
\hline$>4$ & 30 & 2 & $6.70 \%$ & 28 & $93.30 \%$ & \\
\hline \multicolumn{7}{|c|}{ Overall level of knowledge } \\
\hline Good knowledge & 27 & 2 & $7.40 \%$ & 25 & $92.60 \%$ & $0.030^{*}$ \\
\hline Need to be improved & 49 & 14 & $28.60 \%$ & 35 & $71.40 \%$ & \\
\hline \multicolumn{7}{|c|}{ Overall social supports } \\
\hline Good & 20 & 11 & $55.00 \%$ & 9 & $45.00 \%$ & $<0.001^{* *}$ \\
\hline Poor & 56 & 5 & $8.90 \%$ & 51 & $91.10 \%$ & \\
\hline \multicolumn{7}{|c|}{ Modes of transportation } \\
\hline Public & 23 & 10 & $43.50 \%$ & 13 & $56.50 \%$ & $0.004^{* *}$ \\
\hline Own & 53 & 6 & $11.30 \%$ & 47 & $88.70 \%$ & \\
\hline \multicolumn{7}{|c|}{ Convenience of transportation } \\
\hline Inconvenient & 4 & 3 & $75.00 \%$ & 1 & $25.00 \%$ & $0.028^{* *}$ \\
\hline Convenient & 72 & 13 & $18.10 \%$ & 59 & $81.90 \%$ & \\
\hline \multicolumn{7}{|l|}{ Cost of the travel } \\
\hline Unaffordable & 8 & 5 & $62.50 \%$ & 3 & $37.50 \%$ & $0.009^{* *}$ \\
\hline Affordable & 68 & 11 & $16.20 \%$ & 57 & $83.80 \%$ & \\
\hline \multicolumn{7}{|c|}{ Time of waiting for receiving eye care } \\
\hline$\leq 2$ hours & 51 & 15 & $29.40 \%$ & 36 & $70.60 \%$ & $0.011^{* *}$ \\
\hline$>2$ hours & 25 & 1 & $4.00 \%$ & 24 & $96.00 \%$ & \\
\hline \multicolumn{7}{|c|}{ Access to eye care services } \\
\hline Difficult & 33 & 15 & $45.50 \%$ & 18 & $54.50 \%$ & $<0.001^{* *}$ \\
\hline Easy & 43 & 1 & $2.30 \%$ & 42 & $97.70 \%$ & \\
\hline
\end{tabular}

government and non-governmental organization at free cost and from the private clinic with cheap price.

The respondents who had more than 4 family members were more likely to seek eye care from private services. Concerning on level of knowledge on eye care seeking behavior, more than half of the respondents had only moderate level. It may be because there might be some ineffective health education system from ministry of health, poor strengthening program from NGO and uninformative mass media in this study area.

Majority of the respondents well knew about risk factors for the eye problems and comorbidity diseases of eye diseases. Especially, they also knew about the causes of blindness. But, they became a little bit confused about eye problems are associated with old age or not. Moreover, the purpose of respondent to seek eye care depend upon their knowledge because the respondent who understood well about causes and risk factors of eye problems felt confidently and seek eye care more.

All of the respondents accepted seeking eye care regularly is good for eye health and they also knew about once they have eye problem; they need to see the eye doctor/ specialist. It could be due to regular awareness building on seeking eye care in this community by non-governmental organization as well as the impact of good health policy of the government. Some of the respondents thought that because of getting too old, they are not needed to cure your eye problems. Some of them thought that eye screening can be harmful to their eye.

Considering about the convenience of transportation and cost of travel, most of the respondents who received eye care firstly from private services felt that the travel to eye care services was convenient and they also could afford the cost of travel. It may be because this study was conducted only in urban area and so, eye care services were not so far from the respondent's place. 
Regarding the cost of eye care services, most of the respondents who can afford the cost received eye care from private services and those who cannot afford received eye care from government services. It may be due to expensive prices of services from private services.

The study found that there was no significant association between access to eye care service and seeking eye care. However, most of the respondents who felt that they had easy access to eye care services were more likely to seek eye care than those who felt they had difficult access. In this study area, most of the respondents preferred the services which can get effective and easy access eye care services.

\section{Conclusion}

Based on the study findings, the following recommendations have been made in order to precede necessary actions for improving eye care seeking behavior on prevention of blindness among elderly.

1) Implement eye health education programs emphasizing causes and risks factors of eye problems and getting blindness during elderly, consequences of blindness and prevention of blindness etc. at the individual, family as well as at the community and primary care unit level along with implementing primary eye care camps through which elderly can be directly benefited to improve eye care seeking behavior on prevention of blindness.

2) Implement the awareness raising programs/ activities on eye care at the community level giving emphasizing social support from the family members, relatives, friends and neighbors etc. in which elderly could receive enough social supports from different sources and at the different level.

3) Health facilities/ services especially related to elderly eye care need to be fulfilled in all health institutions along with necessary equipment, facilities, enough number of eye health personal, and addressing elderly eye care.

4) Train the health staff on primary eye care at the primary care unit level through whom primary eye care program/ activities could implement emphasizing elderly eye care.

5) Since the community health volunteers and providers from health organizations in Myanmar are considered to be pillars of the public health system, introduce the primary eye care training for them through whom awareness raising activities on elderly eye care could implemented at the community level to promote knowledge level of the community and to enhance the positive attitude towards eye care seeking behavior on prevention of blindness among elderly.

This study has covered very limited areas of elderly eye care to meet objectives to identify eye care seeking behavior on prevention of blindness among elderly and conducted only in urban area of Magway Township among 196 elderly. Therefore, it is recommended as the area of further research to conduct field study extensively throughout both rural and urban area of Magway Township including large sample size and covering all area of eye care seeking behavior on prevention of blindness among elderly which could lead more credibility and hence generalizability to the results.

It recommended to conduct qualitative and in-depth studies covering those all levels to find clear picture of eye care seeking behavior among elderly. Moreover, it is recommended as further area of research to conduct research following interventional community based action research. Therefore, the future study should try to explore some additional factors of the model like belief, perception to find association of eye care seeking behavior.

\section{Acknowledgement}

I would like to express my deepest gratitude to my advisor, Assoc. Prof. Sutham Nanthamonkolchai and my co-advisor Assist. Prof. Chokchai Munsawaengsub for their invaluable feedback, ideas and meaningful suggestions. I owe my gratitude to the president, EC members of Magway Divisional Hospital and professors, assistant surgeon, nurses and staffs of ophthalmology unit of Magway Divisional Hospital for giving the official permission to conduct the study in organization and for cooperating throughout the research for necessary information.

\section{References}

1. United Nations, Department of Economic and Social Affairs, Population Division (2013). World Population Ageing 2013. United Nation Publication; 2002

2. United Nation Population Fund. Myanmar Population and Housing Census 2014. UNFPA Publication;2014.

3. Gopal PP, Rohit K. Prevention of Blindness in Myanmar: Situation Analysis and Strategy for Change. International Agency for Prevention of Blindness and Standard Chartered Bank; 2013.

4. American Family Physician. Common Causes of Vision Loss in Elderly Patients [Internet]. DAVID A. QUILLEN (M.D): Pennsylvania State University College of Medicine, Hershey, Pennsylvania. 1999 60(1):99-108.

5. Fact sheet: Visual impairment and blindness [Internet]. World Health Organization. 2014.

6. Lau JT, Lee V, Fan D, Lau M, Michon J. Attitudes towards and perceptions of visual loss and its causes among Hong Kong Chinese adults. Clin Experiment Ophthalmol. 2004;32(3):243-250. DOI: 10.1111/j.14429071.2004.00811.x

7. World Health Organization. Global Data on Visual Impairments 2010. WHO Publication; 2012.

8. Ministry of Health, Myanmar. Health in Myanmar 2014 [Internet]. MOH Publication; 2014

9. Casson RJ, Newland HS, Muecke J, McGovern S, Durkin S, Sullivan T, et al. Prevalence and causes of visual impairment in rural myanmar: the Meiktila Eye Study. Ophthalmology. 2007;114(12):2302-2308.

10. Myanmar Ministry of Information. Myanmar, facts and figures 2002. Union of Myanmar publication;2002. 